\title{
THE EFFECT OF INSPIRATORY MUSCLE WARM-UP PROTOCOL ON ACCELERATION AND MAXIMAL SPEED IN 12-14 YEARS OLD CHILDREN
}

\author{
Mehmet Ali Çelik, \\ Mustafa Özdali, \\ Mehmet Vural \\ Gaziantep University, \\ Faculty of Sport Science, \\ Gaziantep, Turkey
}

\begin{abstract}
:
The aim of this study is to investigate the effect of the inspiratory muscle warm-up protocol on acceleration and maximal speed in children aged 12-14. Thirty sedentary boys (age: $12.63 \pm 0.89$ years) participated in the study. Participants were randomly included in 4 different trials (T1, T2, T3, T4). Acceleration $(10 \mathrm{~m}, 20 \mathrm{~m})$ and maximal speed tests $(30 \mathrm{~m}, 50 \mathrm{~m})$ were randomly tested at 10 minutes intervals in each trial. Acceleration and speed tests were performed without any warm-up in T1 trial, with general warm-up in T2 trial, placebo inspiratory muscle warm-up in T3 trial, and inspiratory muscle warmup in T4 trial. As a result of the statistical analysis, it was seen that general warm-up (T2) and inspiratory muscle warm-up (T4) increased performance significantly compared to control (T1) and placebo (T3) trials in all acceleration and speed tests ( $p<0.05)$. In conclusion, it can be said that the inspiratory muscle warm-up protocol has positive effects on acceleration and maximal speed performances, similar to general warm-up.
\end{abstract}

Keywords: respiratory, speed, acceleration

\section{Introduction}

In order to achieve the goal in sports, apart from performing the most accurate exercises for the branch and the athlete, the scientific methods are carried out and the athlete's efficiency power is constantly examined. The scientific studies, by looking at the finest details of the exercise, reveal the physical and psychological effects that contribute to athlete efficiency (Hagger, M. \& Chatzisarantis, 2007; Spriet, 2014). Warm-up is a great issue in all sports activities. As a result of the non-targeted warm-up, we may encounter situations such as injury, defeat, not getting the desired efficiency (Bishop, 2003a).

i Correspondence: email ozdalm@hotmail.com 
As detailed in the researches on general warm-up, inspiratory muscle warm-up, respiratory warm-up or respiratory muscle warm-up exercise activities have started to take place in recent years and have contributed positively to performance (Arend et al., 2015; Jung \& Kim, 2015; Volianitis et al., 2001). The effect of respiratory muscle warm-up on performance has been studied by many researchers (Ekelund, 1967; Harms et al., 2000; Harver et al., 1989; Özdal, 2016; Özdal et al., 2016; Özdal et al., 2014; Volianitis et al., 2001). In the present study, the physical performance of inspiratory muscle warm-up will be examined with reference to these previous studies. In this context, the purpose of this study is to investigate effect of inspiratory muscle warm-up protocol on acceleration and maximal speed in 12-14 years old children.

\section{Material Method}

\subsection{Experimental Design and Participants}

This study was designed according to the trial-controlled cross-test design in repeated measurements. Thirty sedentary boys $(12,63 \pm 0,89$ year $)$ participated in the study. In order to determine the number of subjects, a priori test was applied with GPower 3.1 program. The subjects visited the test area 4 times in total. The aim of the study was explained to the subjects during their first visit. In addition, information was given about the tests and devices to be applied and the respiratory muscle warm-up exercise was showed practically. In the second visit, Acceleration $(10 \mathrm{~m}, 20 \mathrm{~m})$ and maximal speed tests $(30 \mathrm{~m}$, $50 \mathrm{~m}$ ) were carried out randomly with intervals of 5 minutes without warm-up. In the third and fourth visit, General (10 min general warm-up and 5 min stretching for the lower extremity) and inspiratory muscle warm-up were randomly performed, and then the acceleration and maximal speed tests were randomly performed with intervals of 5 minutes.

Table 2.1: Descriptive statistics of the participants ( $\mathrm{N}=16)$

\begin{tabular}{|l|c|c|c|c|}
\hline & Min. & Max. & Mean & Std. D. \\
\hline Age (year) & 11,00 & 14,00 & 12,63 & 0,89 \\
\hline Height $(\mathrm{cm})$ & 150,00 & 183,00 & 161,88 & 10,56 \\
\hline Weight $(\mathrm{kg})$ & 35,00 & 55,00 & 44,50 & 6,67 \\
\hline
\end{tabular}

\subsection{Procedures}

\subsubsection{Warm-up Protocol}

For general warm-up exercises, low-intensity aerobic running for 10 minutes, followed by dynamic stretching movements for 5 minutes to stretch the lower extremity muscles (Moran et al., 2017).

\subsubsection{Inspiratory Muscle Warm-up}

Inspiratory muscle warm-up was performed with the inspiratory muscle training device, 30 breaths $\times 2$ sets of $40 \%$ MIP and 1-minute rest between sets in experimental section (Özdal, 2016). 


\subsubsection{Determination Respiratory Muscle Strength}

Electronic respiratory pressure meter (Pocket Spiro MPM-100, Medical Electronic Construction R\&D, Brussels, Belgium) was used for MIP calculation according to the 2002 guidelines of the American Thoracic Society and European Respiratory Society. For MIP measurement, participants performed maximal expiration, immediately following which they were asked to perform maximal inspiration for $1-3 \mathrm{~s}$. The measurements were repeated until the difference between the best two measurements was $5 \mathrm{cmH} 2 \mathrm{O}$, and the best result was recorded in terms of $\mathrm{cmH} 2 \mathrm{O}$ (Kera, 2002).

\subsubsection{Acceleration Performance Measurement (10m and $20 \mathrm{~m})$}

The running distance was 10 and $20 \mathrm{~m}$. Measurements were made by placing a photocell device with a sensitivity of 0.01 seconds at the start and end points of the track. When the athlete was ready after this position, he started running at maximum speed. Measurement results recorded in seconds (Bloomfield et al., 2007).

\subsubsection{Maximal Speed Measurement (30m and 50m)}

Measurements were performed by placing a photocell device with a sensitivity of 0.01 seconds at the start and end points of the 30 and 50 meters track. The test started when the subject ready, and the time started when he passed the starting point by performing the acceleration run $20 \mathrm{~m}$ from the starting point. When it reaches the end point, the time has been stopped (Lesinski et al., 2014).

\subsection{Statistical Analysis}

SPSS 22.0 program was used for statistical analysis. Shapiro-Wilk test was used for normality test. One-way analysis of variance in repeated measures and Bonferoni correction test were used to analyze the difference between trials. Statistical results were evaluated at 0.05 significance levels.

\section{Result}

Table 3.1: Analysis of the change between trails in $10 \mathrm{~m}$ acceleration times

\begin{tabular}{|c|c|c|c|c|c|c|}
\hline & Mean & Std. D. & Std. E. & f & $\mathbf{P}$ & Differences \\
\hline $\mathrm{T} 1$ & 2,45 & 0,31 & 0,093 & \multirow{4}{*}{14.137} & \multirow{4}{*}{0.001} & T2-T1 \\
\hline $\mathrm{T} 2$ & 2,11 & 0,37 & 0,092 & & & T2-T3 \\
\hline T3 & 2,39 & 0,16 & 0,041 & & & T4-T1 \\
\hline $\mathrm{T} 4$ & 2,13 & 0,37 & 0,078 & & & T4-T3 \\
\hline
\end{tabular}

Table 3.1 shows the analysis of the change between trails in $10 \mathrm{~m}$ acceleration times. According to the statistical analysis significant differences were detected between trails $(\mathrm{p}<0.0 .5)$. According to the correction test result, there was significant difference in favor of T2 between T2 and T1-T3, in favor of T4 between T4 and T1-T3 trials. 
Table 3.2: Analysis of the change between trails in $20 \mathrm{~m}$ acceleration times

\begin{tabular}{|c|c|c|c|c|c|c|}
\hline & Mean & Std. D. & Std. E. & f & P & Differences \\
\hline T1 & 4,00 & 0,46 & 0,116 & & & T2-T1 \\
T2 & 3,53 & 0,48 & 0,121 & \multirow{2}{*}{16.476} & \multirow{2}{*}{0.001} & T2-T3 \\
T3 & 3,77 & 0,29 & 0,074 & & & T4-T1 \\
T4 & 3,57 & 0,47 & 0,119 & & & T4-T3 \\
\hline
\end{tabular}

T1; testing with no warm-up, T2; testing with general warm-up, T3; testing with, T4; testing with inspiratory warm-up

Table 3.2 shows the analysis of the change between trails in $20 \mathrm{~m}$ acceleration times. According to the statistical analysis significant differences were detected between trails $(\mathrm{p}<0.0 .5)$. According to the correction test result, there was significance difference in favor of $\mathrm{T} 2$ between $\mathrm{T} 2$ and $\mathrm{T} 1-\mathrm{T} 3$, in favor of $\mathrm{T} 4$ between $\mathrm{T} 4$ and $\mathrm{T} 1-\mathrm{T} 3$ trials.

Table 3.3: Analysis of change between trials in $30 \mathrm{~m}$ maximal speed times

\begin{tabular}{|c|c|c|c|c|c|c|}
\hline & Mean & Std. $\mathbf{D}$. & Std. E. & f & P & Differences \\
\hline T1 & 4,22 & 0,52 & 0,130 & & & T2-T1 \\
T2 & 3,93 & 0,53 & 0,133 & \multirow{2}{*}{6.449} & \multirow{2}{*}{0.006} & T2-T3 \\
T3 & 4,22 & 0,43 & 0,108 & & & T4-T1 \\
T4 & 3,99 & 0,68 & 0,171 & & & T4-T3 \\
\hline
\end{tabular}

T1; testing with no warm-up, T2; testing with general warm-up, T3; testing with, T4; testing with inspiratory warm-up

Table 3.3 shows the analysis of the change between trails in $30 \mathrm{~m}$ maximal speed times. According to the statistical analysis significant differences were detected between trails $(\mathrm{p}<0.0 .5)$. According to the correction test result, there was significance difference in favor of $\mathrm{T} 2$ between $\mathrm{T} 2$ and $\mathrm{T} 1-\mathrm{T} 3$, in favor of $\mathrm{T} 4$ between $\mathrm{T} 4$ and $\mathrm{T} 1-\mathrm{T} 3$ trials.

Table 3.4. Analysis of change between trials in $50 \mathrm{~m}$ maximal speed times

\begin{tabular}{|l|c|c|c|c|c|c|}
\hline & Mean & Std. D. & Std. E. & f & P & Differences \\
\hline T1 & 7,63 & 0,67 & 0,168 & & & T2-T1 \\
T2 & 7,13 & 0,84 & 0,210 & & & T2-T3 \\
\cline { 1 - 4 } T3 & 7,55 & 0,74 & 0,185 & 9.113 & 0.002 & T2-T4 \\
\cline { 1 - 3 } T4 & 7,25 & 0,86 & 0,215 & & & T4-T1 \\
T1 & & & T4-T3 \\
\hline $\begin{array}{l}\text { T1; testing with no warm-up, T2; testing with general warm-up, T3; testing with, T4; testing with } \\
\text { inspiratory warm-up }\end{array}$
\end{tabular}

Table 3.4 shows the analysis of the change between trails in $50 \mathrm{~m}$ maximal speed times. According to the statistical analysis significant differences were detected between trails $(\mathrm{p}<0.0 .5)$. According to the correction test result, there was significant difference in favor of T2 between T2 and T1-T3-T4, in favor of T4 between T4 and T1-T3 trials. 


\section{Discussion and Conclusion}

The purpose of this study was to investigate effect of inspiratory muscle warm-up protocol on acceleration and maximal speed in 12-14 years old children. With this purpose thirty sedentary boys $(12,63 \pm 0,89$ year) participated in the study. In the experimental measurements, general warm-up and respiratory warm-up were performed randomly to the participants. After that, the acceleration and speed test of the subjects were carried out randomly.

In the present study the effects of inspiratory muscle warm-up on performance (10-20 m acceleration, 30-50 m speed test) have been examined compared with different trials. Significant differences were detected in the 10 and $20 \mathrm{~m}$ acceleration tests in favor of the of inspiratory muscle warm-up trials between no-warm-up and placebo warm-up trials. On the other hand, significant differences were determined in the 30 and $50 \mathrm{~m}$ speed test in favor of the of inspiratory muscle warm-up trials between no-warm-up and placebo warm-up trials. The statistical significance in the experimental trials supported the effect of inspiratory muscle training on acceleration and maximal speed.

Additionally, in this study, the effects of general warm-up have been investigated on performance (10-20 m acceleration, 30-50 m speed test) compared with placebo inspiratory warm-up and no-warm-up trials. Significant differences were detected in the 10 and $20 \mathrm{~m}$ acceleration tests in favor of the of general warm-up trials between no-warmup and placebo warm-up trials. However significant differences were determined in the 30 and $50 \mathrm{~m}$ speed test in favor of the general warm-up trials between no-warm-up and placebo and inspiratory warm-up trials. The statistical significance in the experimental trials supported the effect of general warm-up on acceleration and maximal speed.

When previous studies were examined, the effect of especially inspiratory muscle warm-up on acceleration and speed was not investigated much. Conducted studies, the generally effect of inspiratory warm-up on performance has been examined (Arend et al., 2015; Harms et al., 2000; Hartz et al., 2018; Harver et al., 1989; Özdal, 2016; Williams et al., 2002). Inspiratory muscle warm-up and exercise were performed on disabled and sick individuals as well as on healthy individuals and its effect on general health and respiratory functions has been studied (Dall'Ago et al., 2006; Enright et al., 2004; Harver et al., 1989; Okrzymowska et al., 2019).

According to the results from the current study, the positive effect of inspiratory muscle warm-up and general warm-up on speed and acceleration performance can be explained by the stimulation of core muscles and other muscles to achieve better performance. Because the warmed-up muscles becomes more physiologically and physically ready for difference intensity loads (Bishop, 2003b, 2003a). Additionally inspiratory and general warm-up increases the stability of the core muscles, which helps the athletes to perform their movements better and prevent the risk of injury (McConnell AK, 2011).

In summary, considering the positive effects of general and inspiratory muscle warm-up on tested parameters (10-20 m acceleration-30-50 m speed test), it can be 
concluded that inspiratory muscle warm-up can have a positive effect on 10-20 m acceleration-30-50 $\mathrm{m}$ speed performance.

\section{Conflict of Interest Statement}

There are no potential conflicts of interest between authors of this article.

\section{About the Authors}

Mehmet Ali Celik is a Master of Science degree student at Gaziantep University, Turkey. This study is a part of Mehmet Ali Celik's master thesis.

Mustafa Özdal is an associate professor at Gaziantep University, Turkey.

Mehmet Vural is researcher at the Faculty of Sports Sciences at Gaziantep University, Turkey.

\section{References}

Arend, M., Mäestu, J., Kivastik, J., Rämson, R., \& Jürimäe, J. (2015). Effect of inspiratory muscle warm-up on submaximal rowing performance. Journal of Strength and Conditioning Research, 29(1), 213-218.

Bishop, D. (2003a). Warm up I: Potential mechanisms and the effects of passive warm up on exercise performance. In Sports Medicine (Vol. 33, Issue 6, pp. 439-454).

Bishop, D. (2003b). Warm Up II Performance Changes Following Active Warm Up and How to Structure the Warm Up. In Sports Med (Vol. 33, Issue 7).

Bloomfield, J., Polman, R., O’Donoghue, P., \& McNaughton, L. (2007). Effective speed and agility conditioning methodology for random intermittent dynamic type sports. Journal of Strength and Conditioning Research, 21(4), 1093-1100.

Dall'Ago, P., Chiappa, G. R. S., Guths, H., Stein, R., \& Ribeiro, J. P. (2006). Inspiratory muscle training in patients with heart failure and inspiratory muscle weakness: A randomized trial. Journal of the American College of Cardiology, 47(4), 757-763.

Ekelund, L. -G. (1967). Circulatory and Respiratory Adaptation during Prolonged Exercise of Moderate Intensity in the Sitting Position. Acta Physiologica Scandinavica, 69(4), 327-340.

Enright, S., Chatham, K., Ionescu, A. A., Unnithan, V. B., \& Shale, D. J. (2004). Inspiratory muscle training improves lung function and exercise capacity in adults with cystic fibrosis. Chest, 126(2), 405-411.

Hagger, M. \& Chatzisarantis, N. (2007). Social Psychology of Exercise and Sport. McGrawHill International.

Harms, C. A., Wetter, T. J., St. Croix, C. M., Pegelow, D. F., \& Dempsey, J. A. (2000). Effects of respiratory muscle work on exercise performance. Journal of Applied Physiology, 89(1), 131-138. 
Hartz, C. S., Sindorf, M. A. G., Lopes, C. R., Batista, J., \& Moreno, M. A. (2018). Effect of Inspiratory Muscle Training on Performance of Handball Athletes. Journal of Human Kinetics, 63(1), 43-51.

Harver, A., Mahler, D. A., \& Daubenspeck, J. A. (1989). Targeted inspiratory muscle training improves respiratory muscle function and reduces dyspnea in patients with chronic obstructive pulmonary disease. Annals of Internal Medicine, 111(2), 117-124.

Jung, J. H., \& Kim, N. S. (2015). The effect of progressive high-intensity inspiratory muscle training and fixed high-intensity inspiratory muscle training on the asymmetry of diaphragm thickness in stroke patients. Journal of Physical Therapy Science, 27(10), 3267-3269.

Kera, T. (2002). Measurement of respiratory muscle strength. Rigakuryoho Kagaku, 17(4), 265-271. https://doi.org/10.1589/rika.17.265

Lesinski, M., Muehlbauer, T., Büsch, D., \& Granacher, U. (2014). Effekte von Komplextraining auf Kraft- und Schnelligkeitsleistungen bei Sportlern: Ein systematischer Überblick: Effekte von Komplextraining auf sportliche Leistungen. In Sportverletzung-Sportschaden (Vol. 28, Issue 2, pp. 85-107).

McConnell A. K. (2011). Breathe Strong, Perform Better. Human Kinetics.

Moran, J., Sandercock, G., Rumpf, M. C., \& Parry, D. A. (2017). Variation in Responses to Sprint Training in Male Youth Athletes: A Meta-analysis. In International Journal of Sports Medicine (Vol. 38, Issue 1, pp. 1-11). Georg Thieme Verlag.

Okrzymowska, P., Kurzaj, M., Seidel, W., \& Rożek-Piechura, K. (2019). Eight weeks of inspiratory muscle training improves pulmonary function in disabled swimmersA randomized trial. International Journal of Environmental Research and Public Health, 16(10).

Özdal, M. (2016). Acute effects of inspiratory muscle warm-up on pulmonary function in healthy subjects. Respiratory Physiology and Neurobiology, 227, 23-26.

Özdal, M., Bostanci, Ö., Dağlioğlu, Ö., Ağaoğlu, S. A., \& Kabadayi, M. (2016). Effect of respiratory warm-up on anaerobic power. Journal of Physical Therapy Science, 28(7), 2097-2098.

Özdal, M., Dağlıŏlu, Ö., Demir, T., \& Özkul, N. (2014). Aerobik antrenmanın arteriyel hemoglobin oksijen satürasyonu üzerine etkisi. Spor ve Performans Araştırmaları Dergisi, 5(1), 27-34.

Spriet, L. L. (2014). Exercise and Sport Performance with Low Doses of Caffeine. In Sports Medicine (Vol. 44, pp. 175-184). Springer International Publishing. https://doi.org/10.1007/s40279-014-0257-8

Volianitis, S., Mcconnell, A. K., \& Jones, D. A. (2001). Assessment of maximum inspiratory pressure: Prior submaximal respiratory muscle activity ('warm-up') enhances maximum inspiratory activity and attenuates the learning effect of repeated measurement. Respiration, 68(1), 22-27. 
Williams, J. S., Wongsathikun, J., Boon, S. M., \& Acevedo, E. O. (2002). Inspiratory muscle training fails to improve endurance capacity in athletes. Medicine and Science in Sports and Exercise, 34(7), 1194-1198.

Creative Commons licensing terms

Authors will retain the copyright of their published articles agreeing that a Creative Commons Attribution 4.0 International License (CC BY 4.0 ) terms will be applied to their work. Under the terms of this license, no permission is required from the author(s) or publisher for members of the community to copy, distribute, transmit or adapt the article content, providing a proper, prominent and unambiguous attribution to the authors in a manner that makes clear that the materials are being reused under permission of a Creative Commons License. Views, opinions and conclusions expressed in this research article are views, opinions and conclusions of the author(s). Open Access Publishing Group and European Journal of Physical Education and Sport Science shall not be responsible or answerable for any loss, damage or liability caused in relation to/arising out of conflict of interests, copyright violations and inappropriate or inaccurate use of any kind content related or integrated on the research work. All the published works are meeting the Open Access Publishing requirements and can be freely accessed, shared, modified, distributed and used in educational, commercial and non-commercial purposes under a Creative Commons attribution 4.0 International License (CC BY 4.0). 